\title{
Chapter 7 Embedding Employability into an Information Technology Curriculum Using PebblePad: A Practice Report
}

\author{
David Tuffley $^{1}$ and Gayle Brent ${ }^{2}$
}

\begin{abstract}
Commencing their university studies, students benefit from having clear career goals. A vision of their ideal future career can help an otherwise insecure student to cultivate the resilience and determination that endows the forward momentum to keep moving when the going gets tough. Goal-setting helps to re-frame their degree program in their minds as simply a means to an end, rather than an end in itself. A key aspect of this process is to embed a Career Action Plan as an integral element of the assessment plan. This detailed plan is implemented within PebblePad. In this chapter we report on the experience and results of a pilot study using a PebblePad workbook Career Action Plan in 2017 with a cohort of first year, first semester Information and Communication Technology (ICT) students in the course "Fundamentals of Information Technology". It will be seen that the students found the usability of this approach to be beneficial, enabling them to produce an effective Career Action Plan sufficient to warrant the continued use of the method.
\end{abstract}

Keywords: Career Action Plan, goal setting, PebblePad, First year experience, student retention, engagement strategy, Practice Report.

${ }^{1}$ David Tuffley, Snr Lecturer, School of ICT, Griffith University

D.Tuffley@griffith.edu.au

${ }^{2}$ Gayle Brent, L\&T Consultant (Curriculum), Office of the PVC (Griffith Sciences), Griffith University

g.brent@griffith.edu.au 


\section{Introduction}

The challenges for any student starting out at university are many. Not least is their ability to develop sufficient resilience and determination to continue with their studies in the face of the inevitable set-backs and frustrations involved in doing a threeyear professional degree program. An earlier study concluded that students did develop stronger resolve to continue with their studies when they had a clear vision of their future career (Tuffley \& Antonio, 2013). We extend upon the findings of the earlier study by testing the efficacy of a structured online template that enables students to develop a well-structured Career Action Plan.

Commencing students have particular learning needs arising from the social, cultural and academic transition they are in the process of making. Having left the closely supervised secondary school learning environment, they are embarked on "on a journey to becoming self-managing and self-directed learners ... the first-year curriculum should help them get there" (Wong, 2013, p. 130). The greater freedom and autonomy of university can present problems for some students who might be reliant on an external locus of control (Abouserie, 1994) to provide them with a more structured approach to learning (Gifford, Briceno-Perriott, Mianzo, 2006).

We reasoned that a well-structured online template achieves a good balance between a user-friendly approach and "spoon-feeding". When the Career Action Plan template is used, complete with advisory text prompting correct input that is later deleted, the final version might have practical value.

\section{Rationale for approach}

Administering a large first year, first semester course for Information and Communication Technology (ICT) students, conducted across three campuses poses certain practical challenges, one of which is to provide an efficient means for the students to complete the assessment without placing undue emphasis on the formalities submitting work formatted in a specific way etc. One of the perceived strengths of the PebblePad platform is the ability to create well-structured and formatted workbooks and templates which allow for the efficient running of the course. For this reason PebblePad was adopted for this course.

\section{Efficacy of using templates}

The Career Action Plan workbook is implemented in PebblePad. It is a structured, self-authored guide that outlines career goals and associated timelines. This plat- 
form is part of a larger institutional strategy to implement student-friendly curriculum support measures designed to optimize student learning. The potential for this particular tool to establish self-directed, reflective learning has been noted in other case studies (Robbins, 2016). In this project, we use PebblePad to help students think carefully and critically about their desired future career, then provide the means to develop a Career Action Plan that gives shape and meaning to that career, complete with milestones and dates for achievement of intermediate steps.

PebblePad is a Personal Learning Environment. One notable feature that was found to be useful is the ability for students to gather and store templates in one space as they progress through their degree giving a sense of continuity and progression. In addition to the pedagogical advantages of online learning environments, ease of use with an intuitive user interface was considered essential as selection criteria.

The Career Action Plan, the subject of this study, is created at the beginning of the students' journey through university, however it does not end there as it is the starting point for the students' career planning. Considering goals evolve over time, the intention is for the action plan to be revisited in the second and third years and for the student to refine their career goals in light of the knowledge and experience they have acquired as they progress. By the end of their degree, with repeated visits to refine goals, the Career Action Plan will have acquired some authority and momentum in the mind of the student, having invested time and effort in the process. These eventual outcomes will be the subject of future research.

The need to support tertiary ICT students with respect to career planning was explored in depth by McKenzie, Coldwell-Neilson and Palmer (2017). The results of their study affirms that many ICT students will need guidance to develop specific short-term actions that will support their long-term career goals. An action-based Career Action Plan is one mechanism to support students in this process. Miller (2017) likewise advocates for the use of career action planning, with specific reference to the development of a student's analytical thinking skills as integral to the process. She particularly highlights the role of developing a 'Career Narrative' to allow students to develop awareness of what they should focus on in their career planning and development.

\section{Clear goals lead to engagement}

Krause (2005) recommends the development of self-management strategies to enhance student engagement in the first year. Goal-setting and the establishment of a sense of purpose is seen to be part of the engagement process. Krause (2005) asserts the desirability of students becoming resilient, motivated, self-regulated learners who drive their own engagement behaviors in a proactive fashion. This can be seen as a natural and desirable progression from the dependent learning that is character- 
istic of high school. In more specific terms, Chapman (2003) defines the term 'engagement' as a student's cognitive investment in, active participation in and emotional commitment to their learning.

Engagement with one's studies is clearly a factor leading to success (Kuh, 2002) in terms of finishing a program of study. Engagement has been found to give students a more determined attitude towards study, leading to greater satisfaction (Astin, 1993; Pascarella \& Terenzini, 2005). Engagement and satisfaction can be seen as two elements of a dynamic feedback loop that increases the likelihood of success at university.

Earlier research on engagement examined how Web 2.0 technologies, such as social networking tools, can be used to create engaging learning experiences (Wong, 2013; Ebner, Lienhardt, Rohs \& Meyer, 2010; Junco, Heiberger \& Loken, 2010) or, alternatively, at the ways in which tasks that promote higher-order thinking can be utilised in ways that engage students (Laird, Kuh, 2005; Coates et al., 2008; Hockings, Cooke, Yamashita, McGinty, Bowl, 2008). In this project we test PebblePad, a Web 2.0 application being implemented at Griffith University to evaluate its usefulness as an engagement tool.

\section{Creating motivation for goal fulfilment}

The link between goal-setting behaviour and engagement is further illustrated by the strategy employed in this project. A structured and annotated Career Action Plan template is the means by which goals can be enumerated and described in aspirational detail. But how does one create the desire for the achievement of a goal? This is the precursor condition that must be met if the full potential of the template is to be realised.

We take an approach that has its origins in the classical rhetoric of ancient Greece. It has been in continuous use ever since which says much about its efficacy. The technique was refined by the Greeks, and no-one, it seems, has improved on it, though it has been re-stated many times. It basically involves creating an aspirational contrast between one's current state and a more desirable future state (Duarte, 2010). It is a psychological phenomenon that humans innately exhibit; the grass always seems greener on the other side.

The students are asked to consider the same question multiple times, verbally in lectures and in the assignment specification: here is where I am now, where do I want to be in five to ten years? The student, who is likely to be already aspirationally primed at the beginning of their university studies, is encouraged to actively visualise this desirable future state and make an emotional investment in it. Tying it to an assessment item is motivation to make that emotional investment.

The next and perhaps most important step is to reiterate multiple times the contrast between current and future states. The intention is for the students to develop 
an increasing desire for that future state through reiteration of the contrast. In terms of higher education engagement potential, we call this self-reflective goal-setting.

\section{Goal-setting and core belief}

The goals that people set for themselves have been shown to have a defining influence on the core beliefs they have about themselves. Indeed, Erez and Judge (2001) concluded that a student's core beliefs are directly related to the goal-setting behaviour they engage in. It can therefore be argued that having a clearly formulated goal, earnestly desired and reinforced, gives a student a strong sense of identity and purpose. It creates a strong sense of the person they can become. Lacking this strengthened sense of identity and purpose can have a de-motivating effect, as found in Pitkethly and Prosser's study (2010). Students fail or withdraw from university for a variety of reasons, one of which is a failure to make functional adjustments to their thinking, the primary one of which is lack of clearly defined goals.

Goals can be differentiated into two categories; mastery goals and performance goals. Mastery goals concern one's ability, understanding or competence of a subject or skill, while performance goals demonstrate normative competence (Barron \& Harackiewicz, 2001). Both categories of goal are desirable in the students' imagining of future career. For example, a student is encouraged to frame their goal like this: "I will become a recognized expert in Artificial Intelligence (mastery) with a successful track record of innovation in machine learning (performance)". Contrast this with "I want to make robots". The latter has the virtue of simplicity, but the combination of mastery and performance elements gives shape and substance to the goal.

\section{Career management and employability}

Career management skills are a key influencer on graduates' employability, and the role of higher education institutions in this process has come into sharp focus in recent years (Jackson \& Wilton, 2017). The expectation that higher education will actively develop student (and graduate) employability has likewise evolved in line with societal expectation that universities will produce 'work ready' graduates (Weidman, Twale \& Stein, 2001). What has been missing to some extent, is the connection between 'career management' and 'employability' in a curricular context. Bridgstock (2009) emphasises the importance of introducing career management to students early in a degree program, and she likewise notes the absence of 'career management' in many definitions of employability. She comments that this crucial aspect of employability is therefore often missing in the curriculum. 
In the information and knowledge-intensive economies of today and those of the future, the idea of being 'employable' has shifted to emphasise transferable skills and personal attributes in addition to discipline-based knowledge and technical ability (Gilbert, Balatti, Turner \& Whitehouse, 2004). Employers now stress the importance of transferable skills for success in the workplace, with skills and attributes such as time-management, communication, creativity and teamwork frequently ranked as highly valued (Gilbert et al., 2004). Given recent shifts in the nature of work, and the expectation that our current students will experience up to 17 careers (Foundation for Young Australians (FYA), 2017), the need for active and continuous career planning has also escalated. Now more than ever, students and graduates must adopt a proactive mind-set to the career planning process (Bridgstock, 2009) to equip themselves for the challenge of a non-traditional, non-linear career path (FYA, 2017).

The relationship between career planning and developing employability is arguably linked to the career management process itself. Jackson and Wilton (2017) identify that many frameworks for career management include the dimensions of self-awareness (positive self-concept), opportunity awareness (knowledge of labor market trends), decision-making learning (developing career goals and action plans in line with self-concept and perceived capabilities) and transition learning (articulating strengths in relation to job seeking). These frameworks and the concepts explored support the notion that career management involves self-reflective practice that aligns the capabilities and knowledge being developed through study and through life experiences to the capabilities and knowledge required for success in the future. Success in this context includes career satisfaction as an intrinsic element of success in life (Lounsbury, Park, Sundstrom, Williamson \& Pemberton, 2004). In the career management process, students evaluate the relationship between the content of their degree (discipline skills and knowledge), their transferable skills (acquired through university and life experiences) and their personal attributes (character and personality traits), to their aspirational career goals. This would imply they establish a connection between their current experience and their future potential which in turn can inspire deep commitment to their current situation (as a student) to actualise their future success.

Identifying their goals, experiences, skills and capabilities; articulating and evidencing these for the purposes of career planning; and continuously revisiting and realigning their goals to their experiences inherently fosters the development of the students' employability.

\section{Career management and the future of work}

Information and Communication Technology workers of the future are likely to have not one job but a flexible portfolio of part-time or casual jobs that they operate in a more fluid way. This has been called the "gig economy" in the mainstream 
media. In an uncertain employment market, a more flexible approach to career planning is called for (Savickas et al, 2009). With non-linear career paths becoming normal, and given it is impossible to precisely predict what a career in ICT might look like in the future, students need to have a flexible attitude to career planning.

The link between the process of career planning and developing the students'/graduates' ability to identify, articulate, demonstrate and apply their skills in diverse contexts is relevant here. The transferability of capabilities to disparate roles and industries is often not immediately apparent to students or graduates (Bridgstock, 2009), however, when engaged in active career management, students have a guided opportunity to visualise the way their skills and knowledge might be applied in various roles and industries. In the aspirational career planning activity introduced to the first year ICT students, this is manifestly the case. The task created an opportunity for students to visualise the way their skills, knowledge and experiences would be applicable in an unknown future. In the future, graduates will be required to continuously engage in this type of practice to align each of their experiences (skills being developed in one role) with the next (unknown) experience, and to each subsequent (unknown) experience.

\section{Career management and navigating future success}

The nature of jobs in the future workplace are being heavily influenced by increasing automation and digitisation. The research and advisory group, Gartner (2017) estimates that around 1.8 million jobs will be lost by 2020, but 2.3 million will be created in the same period - a net increase of 500,000 over the next two years.

The impact of these changes on career planning for CT students and graduates is related to the concept of 'soft' versus 'hard' skills. Hard skills are those that are discipline-specific, content-based skills; 'soft' skills is terminology often applied to less tangible skill sets and personal attributes - skills like communication, critical thinking, novel and adaptive thinking, entrepreneurship, design, social intelligence, cross-cultural competency, new media literacy, transdisciplinary thinking, cognitive load management and virtual collaboration - to name a few. While intelligent machines can be taught procedural skills, it will be many years before they are capable of having a well-rounded set of 'soft' skills. The key to navigating the future of jobs, then, is to develop both sets of skills equally. Combining and applying discipline-specific knowledge and skills along with creative thinking, dynamic problemsolving, flexibility and adaptability in a way that is beyond the realm of intelligent machines, and in a way that is unique to each individual's talents (Andrews \& Higson, 2008).

Employers of STEM graduates acknowledge that a solid grounding in Science, Technology, Engineering and Maths (STEM) subjects are required. That said, Rayner and Papakonstanitinou (2015) found in their study that the ability to apply knowledge relevant to the discipline is very highly regarded by STEM employers, 
as is the ability to develop knowledge relevant to the position. This aligns with the point that the key to preparing our graduates to effectively navigate the future labour market is to equip them with the skills they need for life-long learning (Leong \& Kavanagh, 2013). Further, we need to provide opportunities for students to identify and reflect on the development of non-discipline specific skills and abilities, as these are equally crucial for success (Miri, David \& Uri, 2007).

Providing students with a platform to guide them through the reflective process, giving them opportunities to evaluate their experiences to identify their capabilities, and providing a process-based learning platform (PebblePad) that enables them to revisit their work and observe and document their own progress, is key to empowering them to develop skills for life-long learning.

\section{Embedding employability for retention}

Students in their first year of university are often challenged to adapt to the new and sometimes daunting environment. Key among these are social challenges (seeking to feel connected) and academic challenges (learning new skills and developing capability) (Lüdtke, Roberts, Trautwein, \& Nagy, 2011; (Lizzio, 2006). The impact of these challenges on student motivation to continue with their study is widely acknowledged (Long, Ferrier, \& Heagneyl, 2006), with universities investing significant time and resources into developing orientation and transition programs to support students through their early weeks at university.

One factor that has significant potential to impact student retention is the development of the student's sense of self-efficacy. One way to achieve this is to create an opportunity for students to align their existing skills and knowledge with the skills and knowledge required for success at university. Establishing a core belief that they have 'what it takes' to succeed, and building confidence for them to apply their existing skills. It is obvious that students do not arrive at university as a blank slate. They will have a range of existing capabilities acquired in the course of their lives to date. It is nonetheless possible for students to lose sight of, and faith in, their own ability in the process of transitioning to the expectations of tertiary education (Lüdtke et al., 2011).

The Career Action Plan activity provides an opportunity for students to reflect on the experiences they had prior to commencing university. It can help them consolidate their understanding of their own skill-sets and abilities (developed through these experiences), and likewise creates a link between previous experiences, ability to succeed at university and future career success. It follows that students who believe they have the skills to succeed at university are more likely to persevere when times are challenging. If they do not think they have the skills to succeed, it may be easier to 'give up' at an early hurdle.

Another important relationship between career planning, including embedding employability, and the improvement of student retention is the notion expressed by 
Lizzio and Wilson (2004) that "the more important we perceive a goal, the more likely we are to seek to achieve it" (p. 110). Embedding the Career Action Plan task in a first year course emphasises to students the extent to which career planning and goal setting is valued. It gives them an opportunity to reinforce and extend on the reasons that inspired them to study. It also encourages students to spend significant time developing and articulating their goals. Implementing the PebblePad template for students to record their action plan creates an excellent context for the reinforcement of their aspirational career goals because it provides a platform to store and revisit their career plan on a regular basis.

\section{Tomorrow's jobs}

An important aspect of the project is to provide "food for thought" for the students' imaginations as they think about their career futures. We know from the broad sweep of history that every generation has the challenge of workplace renewal through the adoption of technology, but what is less often said is that the technology of the future will create many jobs (Gartner, 2017). We may not know what all of those jobs will be called, it is not obvious, but we do know that they will exist. This section outlines what some of these jobs of the future will be.

When R\&D firm, The Future Laboratory (2016), collaborated with Microsoft to bring some clarity for career planners they produced Tomorrow's Jobs. The report predicts some of the more important ICT related jobs of the future.

The Future Laboratory used a method that anyone, including students, can use to good effect. First you look at the patterns coming forward from the past ten or twenty years and then make predictions by projecting the same patterns into the future by extrapolation. Students are told to be proactive about seeing where the world is heading and to position themselves to be prepared when the future arrives.

\section{Virtual habitat designer}

Virtual reality is steadily gaining ground on conventional gaming. It is likely to become a major force in consumer electronics into the future. In China alone around 200 VR companies are absorbing the most talented designers, creating demand globally that have jumped $800 \%$ since 2014 .

VR designers are becoming integral members of product design teams in the creation of new VR experiences running on ever-cheaper but more powerful equipment.

The designers who will be most in demand are those who combine the narrative skill of the game designer with the spatial awareness of the architect, urban designer 
and landscape architect. These are the technologists who will create fascinating virtual worlds that people will not want to leave.

\section{Ethical technology advocate}

Much has been written about robots replacing humans. The narrative often tends towards the scary and sensational. Some process-driven jobs will certainly be automated, particularly those dirty, dangerous or downright boring jobs that humans don't want to do, and for which employers have difficulty finding candidates. But what of the jobs that robots and artificial intelligence (AI) will create?

The robotics engineer, AI specialist and maintenance worker will all be in demand. But we will also need people who advise on how humans and robots should act towards each other. Further, we will need people to teach robots about our strange behaviour so they can react to us in the way that another human might.

These robot ethicists will have the important job of mediating between people and robots, advocating on behalf of the robots. Why? Because the general population may need some convincing that robots are a good thing to have around, and to counter the perception that they are dangerous. In 2016, the German government allocated $€ 200$ million to research this area with other countries set to follow suit.

\section{Digital cultural commentator}

Digital communication is evolving from text-based to being visual (pictures and video). This is already happening as Pinterest and Instagram are growing faster than text-based platforms such as Facebook and Twitter.

By the 2020s, visual communication is likely to be dominant, with multimedia artists, animators and illustrators being in greater demand by organisations wanting to communicate with a mass audience.

Visual skills such as animation will be complemented with music, text, objectoriented programming and augmented reality.

The ideal worker in this field blends advanced technology skills with the humanities. They understand human nature and know how to use the latest technology to create compelling narratives. 


\section{Freelance biohacker}

Open-source software platforms combined with a tremendously information-rich internet are putting the tools of science within the reach of millions who were previously unable to participate in research. This is giving rise to the citizen scientist, who is already proving that remarkable things are possible by motivated amateurs. Beyond this, we will see the growth of crowd-sourcing to find solutions to complex medical and technological challenges. For example, the open-source gene-editing tool CRISPR is being used by thousands of scientists to collaborate in search of cures for depression, schizophrenia, autism and Alzheimer's, to name just a few. By the 2020s, citizen science will have evolved into a viable career for millions of bioscience graduates with an entrepreneurial attitude.

\section{Internet of things data creative}

By 2025, there will be billions of pervasively embedded devices in everyday objects that gather data about many things, the sheer quantity of which defies imagination. We already call this Big Data but it is going to get much bigger. Internet of things data creatives are analysts with creative flair. They not only find the useful information buried in the data, they also know how to tell an engaging story with it.

The job will combine the technical skill of the data scientist with the communication skills of the digital cultural commentator mentioned earlier. Their work will have a major impact in tomorrow's hyper connected world.

\section{Employability capabilities for the future}

When constructing curricula for employability, and testing tools like PebblePad for its implementation, it is important to keep in mind the high-level goal; what overall skills will students need in order to be employable? Any support tool must enable its users to develop the full spectrum of employability skills.

\section{Multi-disciplinary approach}

Students need more than "one string to their bow"- inspiring a multidisciplinary approach in which they combine a range of individually useful skills into a strategic package. If possible, through lateral thinking, these skills might be combined in ways not thought of before. For example, a student might decide to combine data 
science with artificial intelligence and cybersecurity to come up with a unique way to manage the risk of malicious cyber-hacking on safety critical systems. The student might seek ways to take large data sets of historical data and develop algorithms that identify useful patterns obscured within the torrent of data. Once these patterns are identified, strategic defences might be developed. This is an example of the kind of multi-disciplinary approach that makes a student more employable because they have the potential to solve persistent problems, sometimes known as "wicked problems" or the kind that keeps people awake at night with worry.

\section{Stay up-to-date with the latest technology}

Technology students must obviously know how to apply the current technology to solve the kinds of problem that employers have. This is important to get their first job. But in addition to this, they must also be prepared to stay up-to-date as they progress through their careers. They must be willing to resist the temptation midcareer to settle back and "rest on one's laurels" and allow the latest developments to pass them by.

\section{Prototyping mentality}

An aspect of this skill is the prototyping mentality often observed in successful technologists. This involves knowing how to use the latest technology tools to model ideas and create prototypes, then test those prototypes again and again until something really powerful and user-friendly emerges. That excellent end-product never emerges fully formed from the initial idea, it always has to go through repeated prototyping cycles and one has to be prepared to put the time and effort into performing those improvement cycles.

\section{Openness to change}

Having an open mind and being open to new and unfamiliar ideas is vital. The students must come to realize that they should hold few fixed ideas about how things should be done, realizing that orthodox thinking is a straight-jacket for the mind. In the fast-moving technology world, not being an agile thinker will cause a person to be left behind. 


\section{Ethical outlook}

It will be an advantage to be able to operate outside of one's comfort zone to bring about win-win outcomes. Employers value integrity in their employees. They need people who are not afraid to advocate for what is right. A key skill in developing this mind-set is resisting "group-think" and do what is right even when others do not.

Never before has there been such transparency in the way governments and organisations operate. Technology has contributed to this accountability. It is getting harder for criminals and people with malicious intent to get away with their unethical activities. Having ethical employees on-board is a counterbalance and a great asset much valued by organisations.

\section{Resilience}

Understanding that it is not possible to succeed every time at everything one does. This is a valuable employability skill. Students need to learn the inherent lessons from failure and have the determination to try again. This trait is one of the defining characteristics of the successful technology entrepreneurs of Silicon Valley whose motto is "fail early and fail often" because how else will you discover what works except by trying different ways until an optimum solution is identified.

These employability skills fall largely into the "soft skills" category. When combined with the discipline-specific skills of knowing how to program computers and keep them working, the student becomes a more comprehensively skilled potential employee who is more valuable to an organisation than one with well-developed technical skills alone. Recognizing the value of this broad spectrum of skills and putting the effort into acquiring them is the essence of good career management.

\section{PebblePad workflow}

The design and use of the PebblePad worksheet by each group of stakeholders is mapped (see Figure 7.1).. This workflow provides a visual snapshot of the way the academic team and students interact within PebblePad (and within ATLAS - the submission space for student work). 


\section{Career Action Plan - 1004ICT}

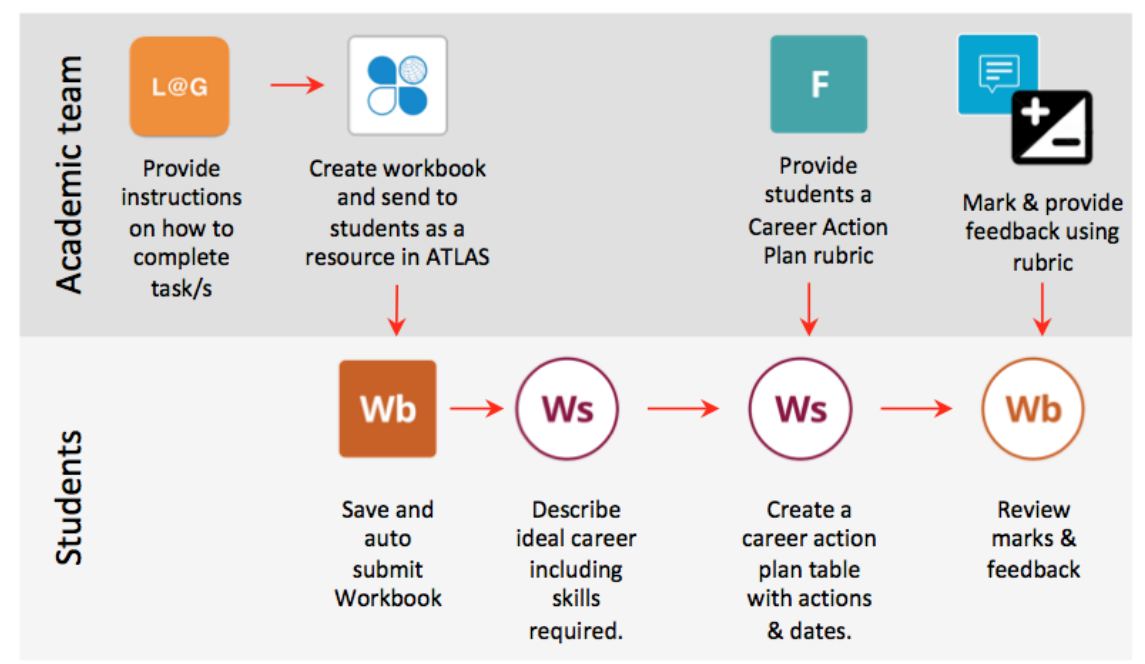

Fig. 7.1 Conceptual overview and workflow of Career Action Plan creation.

\section{Career Action Plan instructions}

The task description, as it appears in the specific Learning@Griffith course website, is shown below:

\section{Career Action Plan (10\%)}

This is essentially a goal setting process aimed at helping you clarify what your most exciting/satisfying future looks like. Once you know this, you can turn it into a plan that lets you transform these aspirations into clearly defined goals and steps to be taken to reach that goal. It serves as encouragement for you to invest the time and energy into making them a reality.

Write 500 or more words on a structured career plan. Examples are provided.

Assessed on evidence that you understand the meaning of 'employable'; as discussed in lectures, and have knowledge of necessary skills; evidence of aspirational mindset.

Due end Week 4. Submission via Pebble+. (see link in L@G side menu)

Instructions:

1. Access PebblePad from your L@G side menu

2. Select the Career Action Plan template

3. Enter your plan into the template (Intro, Stages $1 \& 2$ ) 
4. Your work is automatically saved/submitted as you go. No need to submit separately.

5. Marks and constructive feedback on your plan given within two weeks of the submission date.

Submission instructions are provided in Figure 7.2

\section{Submitting your Action Plan}

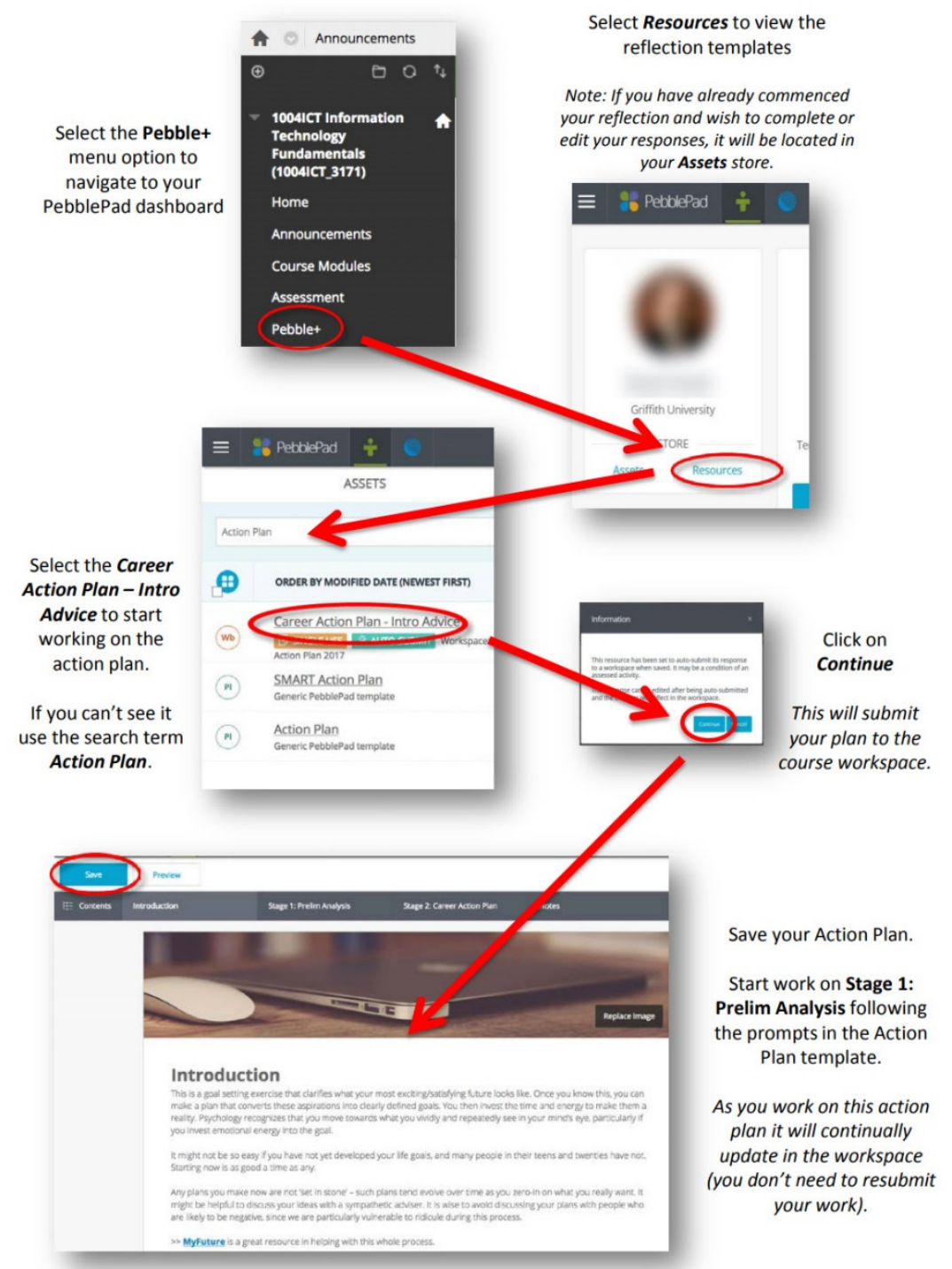


Fig. 7.2 Submission workflow.

\section{Student feedback}

Soliciting feedback on content of courses and the teaching of those courses is a normal part of the overall teaching process. The feedback shown here is drawn from the larger dataset of general feedback. It is the feedback that made some mention of the use of PebblePad to deliver the Career Action Plan task:

- $\quad$ Online templates were made available. Assessments were kept straight to the point. Step by step guides on how to use Pebble.

- I think this course should be taken by every undergraduate first year student. It paves the way and lays the groundwork for something even bigger than our degrees - our career!

- $\quad$ The course is well structured. Content is easy to understand and engage in learning.

- Enjoyable subject focused on preparation and improving yourself for the future

- Self-reflection is a heavily focused topic.

- Assessments were extremely fun and allowed us to understand ourselves more. Gave me ideas of what I want to be after I graduate, made me think about my future.

- The assessment was relevant, shaping into an Information Technology professional does require planning and various facets of skills, not just all technical skills. It did start the process on thinking ahead and looking into the different career paths and exploring the various options open to us.

- Setting goals and realising your capabilities by planning ahead and looking towards the future and how I could be a part of those technological advances.

- $\quad$ Really got me thinking about what I want to achieve in my working and non-working life.

- $\quad$ This course got me really thinking about my future.

- I like how our assignments actually prepare me for potential work.

- It was the only class that inspired me to think about more than just the subject matter.

- $\quad$ The professor was great and assigned work that I feel will truly help me with my future plans and goals. This course really got me thinking about my future and encouraged me to start planning more.

(Student Evaluation of Course, Trimester 1, 2017) 


\section{Conclusion}

The transition to university life is a major rite of passage, particularly for those entering directly from school. It is a period of aspirational change in which the student ideally develops a vision of their future and the motivation to achieve it. Creating the right conditions for the development of these metacognitive skills can be embedded in first year curricula and implemented through the use of appropriate tool sets.

An interactive template was developed in one such technology tool - PebblePad - to guide a cohort of beginning ICT students through an aspirational goal-setting process. This was delivered in the form of an assessment task in which students were required to develop a concrete career action plan. The PebblePad platform is ideal for both the development and 'storage' of this type of work as students can revisit it often during their time at university. They will be encouraged to modify and update their action plan throughout their degree as their goals become clearer.

Evidence from students, provided in the form of feedback through the formal Student Evaluation of Course, suggests that the Career Action Plan activity and assessment was explicitly valued by those students who commented.

While the use of PebblePad to deliver the task was not explicitly mentioned by many, the students' overall appreciation of the task implies they had a positive experience with the PebblePad workbook, and that it was a suitable mechanism for this type of developmental activity. The indications are sufficient to warrant the continued use of the method.

\section{References}

Abouserie, R. (1994). Sources and levels of stress in relation to locus of control and self-esteem in university students. Educational Psychology, 14(3), 323-330.

Andrews, J., \& Higson, H. (2008). Graduate employability, 'soft skills' versus 'hard' business knowledge: A European study. Higher Education in Europe, 33(4), 411-422.

Astin, A. (1993). What matters in college? Four critical years revisited. San Francisco: JosseyBass.

Barron, K., Harackiewicz, J. (2001) Achievement goals and optimal motivation: Testing multiple goal models. Journal of Personality and Social Psychology, 80(5), 706-722.

Bridgstock, R. (2009). The graduate attributes we've overlooked: Enhancing graduate employability through career management skills. Higher Education Research \& Development, 28(1), 31-44. doi.org/10.1080/07294360802444347.

Chapman, E. (2003). Alternative approaches to assessing student engagement rates, Practical Assessment, Research and Evaluation, 8(13), 1-7. Coates, H., Hillman, J., Jackson, D., Tan, L., Daws, A., Rainsford, D. \& Murphy, M. (2008). Attracting, engaging and retaining: New conversations about learning, Australasian Student Engagement Report (AUSSE), Camberwell: ACER.

Duarte, N. (2010). Resonate: Present visual stories that transform audiences. John Wiley \& Sons Ltd. 
Ebner, M., Lienhardt, C., Rohs, M., \& Meyer I. (2010). Microblogs in higher education - a chance to facilitate informal and process-oriented learning. Computers and Education, 55(1), 92-100. doi.org/10.1016/j.compedu.2009.12.006.

Erez, A.' Judge, T. (2001). Relationship of core self-evaluations to goal setting, motivation, and performance. Journal of Applied Psychology, 86(6), 1270-1279.

Foundation for Young Australians. (2017). The new work smarts: thriving in the new work order. https://www.fya.org.au/wp-content/uploads/2017/07/FYA_TheNewWorkSmarts July2017.pdf. Accessed 16 November 2018.

Gartner Group (2017). By 2020, Artificial intelligence will create more jobs than it eliminates. https://www.gartner.com/newsroom/id/3837763. 16 November 2018.

Gifford, D. D., Briceno-Perriott, J., \& Mianzo, F. (2006). Locus of control: Academic achievement and retention in a sample of university first-year students. Journal of College Admission, 191, $18-25$.

Gilbert, R., Balatti, J., Turner, P., \& Whitehouse, H. (2004). The generic skills debate in research higher degrees. Higher Education Research \& Development, 23(3), 375-388.

Hockings, C., Cooke, S., Yamashita, H., McGinty, S. \& Bowl, M. (2008). Switched off: A study of disengagement among computing students at two universities, Research Papers in Education, 23(2), 191-201.

Leong, R., \& Kavanagh, M. (2013). A work integrated learning (WIL) framework to develop graduate skills and attributes in an Australian university's accounting program. Asia-Pacific Journal of Cooperative Education, 14(1), 1-14. doi.org/10.1080/09639284.2018.1454333.

McKenzie, S., Coldwell-Neilson, J., \& Palmer, S. (2017). Informing the career development of IT students by understanding their career aspirations and skill development action plans. Australian Journal of Career Development, 26(1), 14-23. doi:10.1177/1038416217697972

Miri, B., David, B. C., \& Uri, Z. (2007). Purposely teaching for the promotion of higher-order thinking skills: A case of critical thinking. Research in Science Education, 37(4), 353-369.

Krause, K. (2005). Engaged, inert or otherwise occupied? Deconstructing the 21 st century undergraduate student. Keynote paper presented at James Cook University Symposium: Sharing Scholarship in Learning and Teaching - Engaging Students. James Cook University, QLD, Australia, 21-22 September 2005. www.griffith.edu.au/gihe. Accessed 16 November 2018.

Kuh, G. (2002). The National Survey of Student Engagement: Conceptual Framework and Overview of Psychometric Properties. Retrieved 25 June 2013: http://nsse.iub.edu/pdf/conceptual_framework_2003.pdf

Laird, T. \& Kuh, G. (2005). Student experiences with information technology and their relationship to other aspects of student engagement, Research in Higher Education, 46(2), 211-233.

Lizzio, A., \& Wilson, K. (2004). First-year students' perceptions of capability. Studies in Higher Education, 29(1), 109-128.

Lizzio, A. (2006). Designing an orientation and transition strategy for commencing students. A conceptual summary of research and practice. First year experience project. Griffith University, Brisbane.

Long, M., Ferrier, F., \& Heagney, M. (2006). Stay, play Or give it away? Students continuing, changing or leaving university study in first year. Centre for the Economics of Education and Training, Monash University.

Lounsbury, J. W., Park, S. H., Sundstrom, E., Williamson, J. M., \& Pemberton, A. E. (2004). Personality, career satisfaction, and life satisfaction: Test of a directional model. Journal of Career Assessment, 12(4), 395-406.

Lüdtke, O., Roberts, B. W., Trautwein, U., \& Nagy, G. (2011). A random walk down university avenue: life paths, life events, and personality trait change at the transition to university life. Journal of Personality and Social Psychology, 101(3), 620-637. doi: 10.1037/a0023743.

Pascarella, E. T., \& Terenzini, P. T. (2005). How college affects students: Vol. 2. A third decade of research. San Francisco: Jossey-Bass. 
Pitkethly, A., Prosser, M. (2010): The First Year Experience project: A model for university-wide change, Higher Education Research \& Development, 20(2), 185-198. doi.org/10.1080/758483470.

Rayner, G., \& Papakonstantinou, T. (2015). Employer perspectives of the current and future value of STEM graduate skills and attributes: An Australian study. Journal of Teaching and Learning for Graduate Employability, 6(1), 100-115. doi.org/10.21153/jtlge2015vol6nolart576.

Robbins J (2016). Designing a faculty-wide PebblePad strategy for future readiness. In: Poot A (Ed.) Future Ready: Equipping learners for the journey ahead. A collection of case studies from PebbleBash 2016. Telford, UK: Pebble Learning Ltd. 86-93.

Savickas, M. L., Nota, L., Rossier, J., Dauwalder, J. P., Duarte, M. E., Guichard, J., \& Van Vianen, A. E. (2009). Life designing: A paradigm for career construction in the 21st century. Journal of Vocational Behavior, 75(3), 239-250.

The Future Laboratory (2016), available at http://enterprise.blob.core.windows.net/whitepapers/futureproof_tomorrows_jobs.pdf Accessed 17 November 2018.

Tuffley, D., \& Antonio, A. (2013). First year engagement \& retention: A goal-setting approach. Journal of Information Technology Education, 12, 239-251. doi.org/10.28945/1896.

Weidman, J. C., Twale, D. J., \& Stein, E. L. (2001). Socialization of graduate and professional students in higher education: A perilous passage? ASHE-ERIC Higher Education Report, 28 (3). San Francisco, USA: Jossey-Bass, Publishers.

Wong, L. (2013). Student engagement with online resources and its impact on learning outcomes, Journal of Information Technology Education; Innovations in Practice, 12, 129-146. doi.org/10.28945/1829. 